\title{
Malpractice in Procedure of Electro-Convulsive Therapy (ECT) - are we Violating Patient's Rights?
}

\author{
Komal Sabir Dayani ${ }^{1}$ and Sarmad Muhammad Soomar*2 \\ ${ }^{1}$ Trainee Nurse, Aga Khan University Hospital, Pakistan \\ ${ }^{2}$ Senior Research Assistant, Department of Psychiatry, Aga Khan University, Pakistan \\ *Corresponding author: Sarmad Muhammad Soomar, Senior Research Assistant, Department of Psychiatry, Pakistan
}

\begin{tabular}{|c|c|}
\hline ARTICLE INFO & ABSTRACT \\
\hline Received: 慧 February 21, 2019 & Electro-Convulsive Therapy (ECT) is a widely suggested option for psychiatric \\
\hline Published: 慧 February 27, 2019 & \\
\hline $\begin{array}{l}\text { Citation: Komal Sabir D, Sarmad Mu- } \\
\text { nammad S. Malpractice in Procedure } \\
\text { f Electro-Convulsive Therapy (ECT) } \\
\text { - are we Violating Patient's Rights?. } \\
\text { Biomed J Sci \& Tech Res 15(2)-2019. }\end{array}$ & $\begin{array}{l}\text { in lieu of providing therapy that is not at all acceptable. It is similar to harming patients in } \\
\text { psychiatric services rather helping them to recover. The basic paper is written on reflecting } \\
\text { convictions of this procedure observed in various settings and it is recommended to } \\
\text { maintain morality, consider rights of patients and work on various soft skills and procedure } \\
\text { skills while using ECT in psychiatric practices. }\end{array}$ \\
\hline
\end{tabular}
BJSTR. MS.ID.002671.

Keywords: Psychiatry; Electro Convulsive Therapy; Rights; Malpractice

\section{Introduction}

Health is not based on absence of illness, but it is a matter that balances our physical, mental, spiritual and sexual aspects of life [1]. Talking about the mental health is one of those aspects which is most neglected and stigmatized refraining people to even seek proper and timely help [2]. Ongoing basis we definitely see lots of clients requiring various treatment for maintaining their mental wellness [3]. Application of Electro-Convulsive Therapy (ECT) is one of the treatment modalities used in Pakistan [4]. Providing electric current in a controlled manner to human brain has been reliably one of the effective treatments for various mental health disorders [5]. The primary indications for this therapy are Major Depression, Mania and sometimes Schizophrenia [6]. Journey of ECT began in 1979 when Italian psychiatrist Ugo Celetti and Lucio Binin performed it for the first time in Rome [7].

ECT is the safe induction of Grand mal (generalized) seizures through electric current to the brain [8]. Despite of its wide usage, ECT continues to be the most stigmatized treatment as described in a very famous publication called "flew over the cuckoo's next", which talked about ECT in horrific terms [9]. This misconception is due to the poor treatment practices, cinematic portrayal of electroconvulsive therapy and invalid sources of information which influenced opinions of millions [10]. Today, It is regarded the safe and quicker treatment than any other drug if administered in medically sound manner, following the standards of biomedical ethics. Over the years this technique has been modified with the addition of Anesthesia to achieve amnesia and pain free procedure, muscle relaxant and oxygenation to eliminate musculoskeletal injury and to aid in airway management during the procedure [11].

\section{Discussion}

According to the mental health ordinance Pakistan [12], "Specialized psychiatric treatment is to be carried out with informed consent of the patient in writing, or relative or guardian if patient is a minor or lacks competency also, electroconvulsive therapy shall be administered in general anesthesia". This should only be performed by qualified psychiatrist in an appropriate setting [6]. Also basic requirements of informed consent for ECT were proposed by American Psychiatric Association Task Force [13], It is mandatory to provide adequate information to the patient and family and opportunity to consent. Yet, many psychiatric hospitals operating in developing countries fail to provide the quality mental health care, by still using unmodified electroconvulsive therapy; which is not taken as a treatment rather depicted as a 
brutally abusive maneuver, lack of public acceptance, negative depiction and techniques used by untrained professionals results in confirmation of false beliefs about ECT. The feeling of betrayal, unworthiness, hopelessness and low self-esteem further escalates the vulnerability to stressors leading poor communication and eventually unwillingness to participate in the procedure.

This is also violating the ethical principles of autonomy, beneficence, non-maleficence and justice [14]. What made us look into this issue is continuous observations that we witnessed on various clinical placements in a city of Pakistan, where ECT and other psychiatric services are available. These mal practices include untrained professionals, no use of anesthetic while providing therapy, lack of empathy and emotional connection with client, practitioners are unaware of history, nurses are not handling and care clients prior or post to procedure, no educational teaching is given to client or family and many more unacceptable events. For patients receiving this treatment is deeply and long lastingly traumatic experience of their lives and affects every aspect of their health. Often unmodified ECT results in physical injuries like joint dislocation, spinal fractures and cognitive impairments. But it is widely seen to be practiced in Pakistan, not everywhere but in many of the therapy providing centers.

Furthermore, it also affects limbic system of brain which is affected by deep trauma. Lack of knowledge and attitude of staff make patients feel ashamed, hopeless, afraid and anxious. The debate here is not whether to get or not get ECT but the malpractice in administering ECT regarding violation of ethical principles. At the very least, patient should receive the treatment following the same human rights, ethical standards and quality. Dilion developed a model for engaging with the patient and family based on five-step interventions in collaboration of ECT team with staff for successful procedure [15], and this is very fruitful adding here in the table below to connect with the unacceptable situation of performing ECT in some of the medical centers and platform (psychiatric) witnessed (Table 1)

Table 1.

\begin{tabular}{|c|c|c|}
\hline 1 & $\begin{array}{c}\text { Assessment and development of a } \\
\text { therapeutic relationship }\end{array}$ & $\begin{array}{c}\text { Refers to the assessment and development of therapeutic relationship by establishing rapport, } \\
\text { asking relevant questions to assist and identify the condition of the patient and talking consent. }\end{array}$ \\
\hline 2 & Exploring fears and concerns & $\begin{array}{r}\text { Encouraging patient to express fears and concerns instead of assuming and this emphasis on the } \\
\text { communication of patient both verbal and nonverbal. }\end{array}$ \\
\hline 3 & Identifying teaching tools & $\begin{array}{c}\text { It provides the team with an opportunity to answer the questions of patient and family. To share } \\
\text { basic information about the procedure through different ways like brochures and tools. }\end{array}$ \\
\hline 4 & Anxiety reduction coping strategies & $\begin{array}{c}\text { Identifying the coping strategies of the patient which help them to cope and teaching patient } \\
\text { relaxation techniques to reduce anxiety and working on strengthening their coping skills. }\end{array}$ \\
\hline 5 & Evaluation & $\begin{array}{c}\text { Evaluating the problems and information provided. Encouraging patient to keep a record of their } \\
\text { things in a journal to ensure access when patients suffers from temporary memory loss after the } \\
\text { treatment. }\end{array}$ \\
\hline
\end{tabular}

\section{Recommendations \& Conclusion}

The most important role of a care providers (nurse, student nurses, physicians, people who do the procedure) in mental health setting is to provide support to the patients for psychological wellbeing. Attention should be given towards educating the patients and families about the procedure, consent, side effects, benefits and outcomes. All the patients have right to take or refuse care or procedure. By doing risk-benefit analysis we can also maintain both respects of ethical principles i.e. autonomy vs. beneficence. Moreover, Proper pre and post education and intervention should be done. Team involved in the treatment should review own knowledge to prevent confusions. Patients should be provided with correct and adequate information about the process. A checklist for procedure (pre, intra, post) is another beneficial option.

In conclusion, Electro-Convulsive Therapy has proven to be the effective treatment for various mental disorders, but approach should be therapeutic to ensure the psychological benefit of this activity. However, witnessed cases in many of the services center around the city it is very difficult to ensure proper safety of clients that is why a simple procedure can become very harmful. As, caregivers of psychiatric clients we all as a team should cooperate to bring a better care of patients with maintaining proper protocols of the procedure.

\section{References}

1. (2018) World Health Organization: definition of Health.

2. Clement S, Schauman O, Graham T, Maggioni F, Evans Lacko S, et al. (2015) What is the impact of mental health-related stigma on helpseeking? A systematic review of quantitative and qualitative studies. Psychological medicine 45(1): 11-27.

3. Gureje O, Nortje G, Makanjuola V, Oladeji BD, Seedat S, et al. (2015) The role of global traditional and complementary systems of medicine in the treatment of mental health disorders. The Lancet Psychiatry 2(2): 168177.

4. Ahmadi N, Moss L, Hauser P, Nemeroff C, Are Vaidya N (2018) Clinical outcome of maintenance electroconvulsive therapy in comorbid Posttraumatic Stress Disorder and major depressive disorder. Journal of psychiatric research 105: 132-136.

5. Redlich R, Opel N, Grotegerd D, Dohm K, Zaremba D, et al. (2016) Prediction of individual response to electroconvulsive therapy via machine learning on structural magnetic resonance imaging data. JAMA psychiatry 73(6): 557-564. 
6. Kellner CH, Pritchett JT, Beale MD, Coffey CE. Handbook of ECT.

7. Payne N, Prudic J (2009) Electroconvulsive Therapy: Part I. A Perspective on the Evolution and Current Practice of ECT. Journal Of Psychiatric Practice 15(5): 346-368.

8. Townsend M (2015) Psychiatric mental health nursing.

9. Otto KW (2017) Seven Flew over the Cuckoo's Nest: Under What Circumstances Is the Defense of Lack of Mental Responsibility Successful. Army Law 4.

10. Della Cava E (2018) 10 Myths about ECT. Current Psychiatry17(7) :9-28.

11. Acharya H, Gaur A, Kunigiri G (2018) Anesthetic and psychiatric implications of accidental awareness under general anesthesia during electroconvulsive therapy. Saudi journal of anesthesia 12(2): 335-338.

\section{ISSN: 2574-1241}

DOI: 10.26717/BJSTR.2019.15.002671

Sarmad Muhammad Soomar. Biomed J Sci \& Tech Res

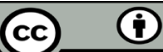

This work is licensed under Creative Commons Attribution 4.0 License

Submission Link: https://biomedres.us/submit-manuscript.php
12. Tareen A, Tareen KI (2016) Mental health law in Pakistan. BJ Psych international 13(3):67-69.

13. Task force reports. American Psychiatric Association

14. Kangasniemi M, Pakkanen P, Korhonen A (2015) Professional ethics in nursing: an integrative review. Journal of advanced nursing 71(8): 17441757.

15. Dillon DG, Pizzagalli DA (2018) Mechanisms of memory disruption in depression. Trends in neurosciences 41(3): 137-149.

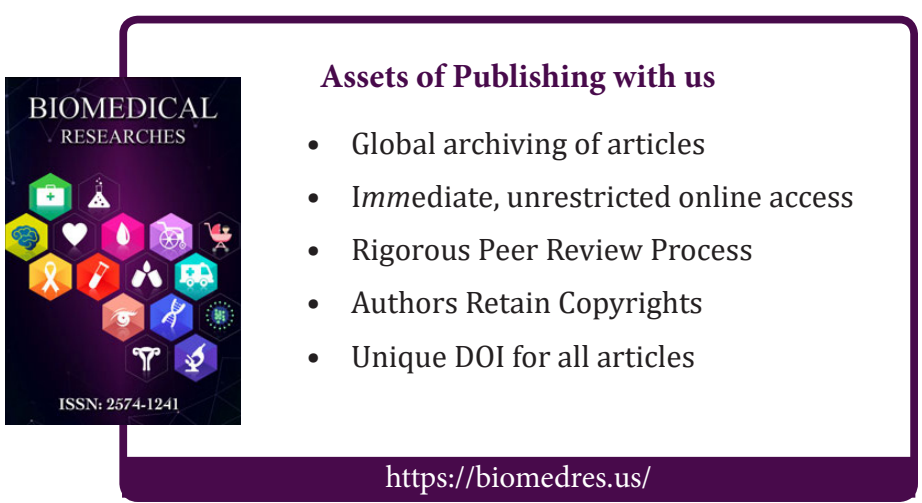

